\title{
Comparison of distinctive models for calculating an interlobar emphysema heterogeneity index in patients prior to endoscopic lung volume reduction
}

\author{
This article was published in the following Dove Press journal: \\ International Journal of COPD \\ I June 2017 \\ Number of times this article has been viewed
}

\author{
Dorothea Theilig' \\ Felix Doellinger' \\ Alexander Poellinger' \\ Vera Schreiter' \\ Konrad Neumann ${ }^{2}$ \\ Ralf-Harto Hubner ${ }^{3}$ \\ 'Department of Radiology, Charité \\ Campus Virchow Klinikum, Charité, \\ Universitätsmedizin Berlin, Berlin, \\ Germany; ${ }^{2}$ Institute of Biometrics \\ and Clinical Epidemiology, Charité \\ Campus Benjamin Franklin, \\ Charité, Universitätsmedizin Berlin, \\ Berlin, Germany; ${ }^{3}$ Department of \\ Pneumology, Charité Campus Virchow \\ Klinikum, Charité, Universitätsmedizin \\ Berlin, Berlin, Germany
}

Background: The degree of interlobar emphysema heterogeneity is thought to play an important role in the outcome of endoscopic lung volume reduction (ELVR) therapy of patients with advanced COPD. There are multiple ways one could possibly define interlobar emphysema heterogeneity, and there is no standardized definition.

Purpose: The aim of this study was to derive a formula for calculating an interlobar emphysema heterogeneity index (HI) when evaluating a patient for ELVR. Furthermore, an attempt was made to identify a threshold for relevant interlobar emphysema heterogeneity with regard to ELVR.

Patients and methods: We retrospectively analyzed 50 patients who had undergone technically successful ELVR with placement of one-way valves at our institution and had received lung function tests and computed tomography scans before and after treatment. Predictive accuracy of the different methods for HI calculation was assessed with receiver-operating characteristic curve analysis, assuming a minimum difference in forced expiratory volume in 1 second of $100 \mathrm{~mL}$ to indicate a clinically important change.

Results: The HI defined as emphysema score of the targeted lobe (TL) minus emphysema score of the ipsilateral nontargeted lobe disregarding the middle lobe yielded the best predicative accuracy ( $\mathrm{AUC}=0.73, P=0.008$ ). The $\mathrm{HI}$ defined as emphysema score of the TL minus emphysema score of the lung without the TL showed a similarly good predictive accuracy (AUC $=0.72$, $P=0.009$ ). Subgroup analysis suggests that the impact of interlobar emphysema heterogeneity is of greater importance in patients with upper lobe predominant emphysema than in patients with lower lobe predominant emphysema.

Conclusion: This study reveals the most appropriate ways of calculating an interlobar emphysema heterogeneity with regard to ELVR.

Keywords: CT-quantitative, COPD, emphysema heterogeneity, endoscopic lung volume reduction

\section{Introduction}

In recent years, more and more insight has been gained into endoscopic lung volume reduction (ELVR) as a treatment option for patients with severe COPD and concomitant emphysema. ${ }^{1-10}$ Several criteria for identifying patients who might benefit from ELVR and the lung lobe to be treated to achieve the best outcome have been proposed. An important criterion is interlobar emphysema heterogeneity. ${ }^{1,11,12}$ Put simply, the impact of interlobar emphysema heterogeneity on the outcome of ELVR
Correspondence: Dorothea Theilig

Department of Radiology, Charité

Campus Virchow Klinikum,

Charité, Universitätsmedizin

Berlin, Augustenburger Platz I,

I 3353 Berlin, Germany

Tel +493045065 7I49

Fax +49304507553928

Email dorothea.theilig@charite.de
International Journal of COPD 2017:12 |63|-1640

$163 \mid$

Dovepress if in 0

http://dx.doi.org/10.2147/COPD.S133348 (c) (1) (5) 2017 Theilig et al. This work is published and licensed by Dove Medical Press Limited. The full terms of this license are available at https://www.dovepress.com/terms.php cc. ${ }_{\mathrm{BY}} \mathrm{NC}$ and incorporate the Creative Commons Attribution - Non Commercial (unported, v3.0) License (http://creativecommons.org/licenses/by-nc/3.0/). By accessing the work you hereby accept the Terms. Non-commercial uses of the work are permitted without any further permission from Dove Medical Press Limited, provided the work is properly attributed. For permission for commercial use of this work, please see paragraphs 4.2 and 5 of our Terms (https://www.dovepress.com/terms.php). 
can be summed up as follows: if the lung lobes differ in the amount of emphysema, that is, the amount of damaged lung parenchyma, and the most afflicted lung lobe is eliminated with ELVR by inducing atelectasis, outcome is better than if the entire lung is affected equally and one lobe is removed by ELVR. While many studies found a significant impact of interlobar emphysema heterogeneity on outcome after ELVR, others did not. ${ }^{13}$

There are many different ways one could possibly define interlobar emphysema heterogeneity, and a standardized definition does not exist. In the VENT trial, the "percentage of heterogeneity was defined as the difference in quantitative emphysema score between the targeted lobe and the ipsilateral adjacent nontargeted lobe" disregarding the middle lobe. ${ }^{1}$ On the other hand, Valipour et al, for example, defined the interlobar heterogeneity index (HI) as the tissue destruction of the targeted lobe (TL) divided by the tissue destruction of the ipsilateral nontargeted (INTL) lobe, disregarding the middle lobe and lingual. ${ }^{14}$

The aim of this study was to find a definition of $\mathrm{HI}$ that best predicts the outcome of ELVR. To that end, we determined the HI in six different ways that we found theoretically reasonable with regard to ELVR and compared the results with the improvement of the forced expiratory volume in 1 second $\left(\mathrm{FEV}_{1}\right)$ after ELVR by performing a receiveroperating characteristic (ROC) analysis.

We focused on $\mathrm{FEV}_{1}$ as the output parameter, for it seems to be the only output parameter that emphysema heterogeneity has a relevant impact on as shown in the study recently published by Thomsen et al. ${ }^{12}$ Nevertheless, other output parameters such as the residual volume (RV), the St George's Respiratory Questionnaire (SGRQ) and the 6-minute walk test (6MWT) were briefly analyzed, too, using the same statistical method.

\section{Patients and methods}

The study was approved by the ethics committee of the Charité (EA1/213/16). It was a retrospective study from medical records. All patients were anonymized prior to data analysis. Based on the votum of the local ethic committee, informed consent forms were not required for this study.

\section{Patient population}

We retrospectively analyzed 62 patients who underwent ELVR with placement of one-way silicone Zephyr valves (Pulmonx, Redwood City, CA, USA) at our institution and had received lung function tests and computed tomography (CT) scans acquired in inspiration before and after ELVR.

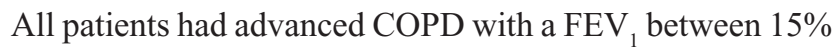

and $45 \%$ of the predicted value, a RV of at least $150 \%$ of the predicted value and a total lung capacity of $>100 \%$ at baseline after reversibility testing. Most patients completed the SGRQ and the 6MWT before and after treatment. All patients had been nonsmokers for at least 3 months at the time of treatment, as proven by serum carboxyhemoglobin levels of $<2 \%$. The TL for ELVR was selected on the basis of visually estimated degree of emphysema, perfusion, and the absence of collateral ventilation determined by the Chartis system (Pulmonx) as described in the literature. ${ }^{15,16}$ All patients underwent ELVR with an entire lobe treated as recommended by previous studies. ${ }^{3,17}$ Out of the 62 patients analyzed in this study, 24 patients showed a tendency toward upper lobe predominant emphysema in visual assessment and received upper lobe treatment while 38 patients showed a tendency toward lower lobe predominant emphysema and received lower lobe treatment.

As described in the literature, a TL volume reduction of $>350 \mathrm{~mL}$ was considered a technically successful treatment. ${ }^{18}$ Out of the 62 evaluated patients, 12 did not meet this criterion and were therefore excluded, leaving 50 patients for the final analysis. Descriptive statistics of these 50 patients are summarized in Table 1.

\section{High-resolution computed tomography with quantitative analysis}

All patients underwent a CT scan (Light Speed Ultra 8, General Electric, Boston, MA, USA) for target lobe selection and emphysema evaluation at baseline and for follow-up around 3 months after endoscopic valve implantation. The CT protocol was identical for all scans and included a slice thickness of $1.25 \mathrm{~mm}, 120 \mathrm{kVp}$, and $100 \mathrm{mAs}$. The scans were obtained in deep inspiration without intravenous contrast medium administration. We retrospectively performed quantitative analysis of the chest CT scans using the MeVisPULMO 3D software, version 3.42 (Fraunhofer

Table I Descriptive statistics of the study population $(n=50)$

\begin{tabular}{lllll}
\hline Parameter & Minimum & Maximum & Mean & SD \\
\hline Lung volume in $\mathrm{mL}$ & 4,488 & 10,122 & 6,870 & $\mathrm{I}, 338$ \\
$\begin{array}{l}\text { Targeted lobe volume } \\
\quad \text { in } \mathrm{mL}\end{array}$ & 934 & 2,758 & $\mathrm{I}, 732$ & 405 \\
$\begin{array}{c}\text { Emphysema score of the } \\
\quad \text { lung in \% }\end{array}$ & 14 & 52 & 30 & 9 \\
$\begin{array}{c}\text { Emphysema score of the } \\
\text { targeted lobe in \% }\end{array}$ & 17 & 63 & 38 & 12 \\
$\begin{array}{c}\text { Volume difference of } \\
\text { the targeted lobe } \\
\text { after ELVR in } \mathrm{mL}\end{array}$ & $-2,34 \mathrm{I}$ & -362 & $-1,26 \mathrm{I}$ & 502 \\
\hline
\end{tabular}

Abbreviations: ELVR, endoscopic lung volume reduction; SD, standard deviation. 
MEVIS, Bremen, Germany), which enables quantification of emphysematous lung parenchyma by determining the emphysema score defined as the ratio of voxels with a density below a certain threshold to the total number of voxels in the region of interest. ${ }^{19} \mathrm{We}$ chose a threshold of $-950 \mathrm{HU}$ as proposed in previous studies. ${ }^{20-22}$ Furthermore, we used the software for semiautomatic segmentation of the lung into the lung lobes (left upper lobe, left lower lobe, right upper lobe, right middle lobe, and right lower lobe) as described in the literature. ${ }^{19,23}$ See also example in Figure 1.

\section{Heterogeneity index}

The HI was calculated from the emphysema scores of the lung lobes determined from CT scans acquired in inspiration. We used six different methods for calculating the HI based on definitions found in the literature and those we found theoretically feasible with regard to ELVR. ${ }^{1,14}$ The methods to calculate the HI differ in whether only the ipsilateral half of the lung or the entire lung is taken into account, whether the middle lobe of the right half of the lung is neglected or not, and whether the emphysema scores of the respective lung lobes are subtracted from each other or divided by each other. The exact definitions and main characteristics of the HIs used and compared in this analysis are summarized in Tables 2 and 3.

In addition to that, there are other approaches to the HI like emphysema scores weighted for volume and HIs

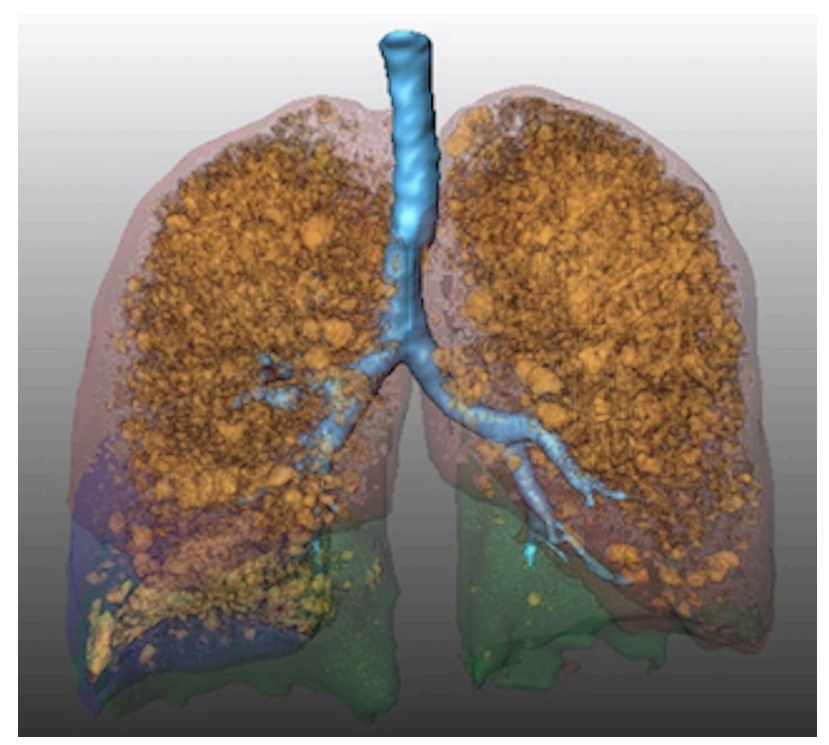

Figure I Coronary 3D surface view of a processed HRCT scan of the lung acquired in inspiration depicting the lung lobes (semitransparent green, lower lobes; semitransparent red, upper lobe; semitransparent blue, right middle lobe) and voxels with a density below $-950 \mathrm{HU}$ (orange).

Note: The calculated emphysema scores, that is, percentages of voxels below $-950 \mathrm{HU}$ in a lung lobe to the total number of voxels in that lobe, were as follows: right upper lobe $26.4 \%$, right middle lobe $16.0 \%$, right lower lobe $14.9 \%$, left upper lobe $27.8 \%$, and left lower lobe $4.9 \%$.

Abbreviation: HRCT, high-resolution computed tomography.
Table 2 Definitions of the six interlobar emphysema heterogeneity indices investigated in our study

\begin{tabular}{|c|c|}
\hline $\begin{array}{l}\text { Heterogeneity } \\
\text { index }\end{array}$ & Definition \\
\hline$\overline{\mathrm{HI} \mathrm{I}}$ & $\begin{array}{l}\text { TL emphysema score/emphysema score of the } \\
\text { INTL, excluding middle lobe }\end{array}$ \\
\hline $\mathrm{HI} 2$ & $\begin{array}{l}\text { TL emphysema score/emphysema score of the } \\
\text { INTL, including middle lobe }\end{array}$ \\
\hline HI 3 & $\begin{array}{l}\text { TL emphysema score/emphysema score of the } \\
\text { whole lung without TL }\end{array}$ \\
\hline $\mathrm{HI} 4$ & $\begin{array}{l}\text { TL emphysema score - emphysema score of the } \\
\text { INTL, excluding the middle lobe }\end{array}$ \\
\hline HI 5 & $\begin{array}{l}\text { TL emphysema score - emphysema score of the } \\
\text { INTL, including the middle lobe }\end{array}$ \\
\hline $\mathrm{HI} 6$ & $\begin{array}{l}\text { TL emphysema score - emphysema score of the } \\
\text { whole lung without } T L\end{array}$ \\
\hline
\end{tabular}

Note: Emphysema score $=$ ratio of the number of voxels with an attenuation $<950 \mathrm{HU}$ to the total number of voxels in the region of interest.

Abbreviations: HI, heterogeneity index; INTL, ipsilateral nontargeted lobe; TL, targeted lobe.

calculated from the tissue to air ratio. The latter version has been frequently used in bronchoscopic thermal vapor ablation trials. ${ }^{24-26}$ In this study, both these approaches have been assessed separately in addition to the aforementioned HIs. The respective analyses are shown in Tables S1-S3.

\section{Statistical analysis}

Predictive accuracy of the six different HIs was assessed by ROC curve analysis, assuming a minimum difference in $\mathrm{FEV}_{1}$ of $100 \mathrm{~mL}$ to indicate a minimal clinically important difference (MCID), as proposed in the literature. ${ }^{27-30}$ In addition to that, other output parameters such as RV, 6MWT, and SGRQ were assessed with the same method using a MCID of $0.31 \mathrm{~L}, 26 \mathrm{~m}$, and 4 units, respectively, as suggested in the literature. ${ }^{29,30}$

The critical value was determined by the point on the ROC curve with the shortest distance to the upper left corner, that is, $100 \%$ sensitivity and $100 \%$ specificity. ${ }^{31}$ This distance (D) was calculated using the following formula: $\mathrm{D}=\sqrt{ }\left([1-\text { sensitivity }]^{2}+[1-\text { specificity }]^{2}\right)$. In order to test for statistically significant differences, pairs of heterogeneity scores were compared using DeLong's test for two correlated ROC curves. ROC analysis was performed using IBM SPSS Statistics 19.0.0 (IBM Corporation, Armonk, NY, USA) and $\mathrm{R}$ version 3.3.0 with the package "pROC" version 1.8. A $P$-value $<0.05$ was considered statistically significant.

\section{Results}

Of the 62 patients who had undergone ELVR at our institution and had received lung function tests and CT scans before and after ELVR, 50 showed a reduction in TL volume of $>350 \mathrm{~mL}$. Out of these 50 patients, 32 showed an increase 
Table 3 Overview of the major characteristics of the interlobar emphysema heterogeneity indices investigated in this study

\begin{tabular}{|c|c|c|c|c|c|c|}
\hline \multirow{2}{*}{$\begin{array}{l}\text { Heterogeneity } \\
\text { index }\end{array}$} & \multicolumn{6}{|c|}{ Characteristics } \\
\hline & Ratio & $\begin{array}{l}\text { Absolute } \\
\text { difference }\end{array}$ & $\begin{array}{l}\text { Ipsilateral half } \\
\text { of the lung }\end{array}$ & Whole lung & $\begin{array}{l}\text { Exclusion of the } \\
\text { right middle lobe }\end{array}$ & $\begin{array}{l}\text { Inclusion of } \\
\text { middle lobe }\end{array}$ \\
\hline HI I & + & - & + & - & + & - \\
\hline $\mathrm{HI} 2$ & + & - & + & - & - & + \\
\hline $\mathrm{HI} 3$ & + & - & - & + & - & + \\
\hline HI 4 & - & + & + & - & + & - \\
\hline HI 5 & - & + & + & - & - & + \\
\hline HI 6 & - & + & - & + & - & + \\
\hline
\end{tabular}

Notes: +, applicable; -, not applicable.

Abbreviation: $\mathrm{HI}$, heterogeneity index.

in $\mathrm{FEV}_{1}$ of more than $100 \mathrm{~mL}$ after ELVR, that is, had a difference classified as clinically relevant, and 18 did not. In the ROC analysis, most of the six emphysema HIs investigated in this study showed statistically significant discriminatory capacity between clinically successful treatment, that is, an increase in $\mathrm{FEV}_{1}$ of $>100 \mathrm{~mL}$, and clinically unsuccessful treatment, that is, an increase in $\mathrm{FEV}_{1}$ of $<100 \mathrm{~mL}$ (Table 4). $\mathrm{HI}$, which is defined as emphysema score of the TL minus emphysema score of the INTL disregarding the middle lobe, yielded the best predicative accuracy ( $\mathrm{AUC}=0.73, P=0.008$ ). HI 6, which is defined as emphysema score of the TL minus emphysema score of the lung without the TL, showed a similarly good predictive accuracy (AUC $=0.72, P=0.009$ ). More generally speaking, the ROC analysis indicates that subtracting the percentages of emphysematous lung volume of the lobes in question yields a better predictive accuracy than dividing them. However, DeLong's test showed no statistically significant differences between the ROC curves of HI 4 and HI 6 ( $P=0.543)$. The DeLong's test did show statistically significant differences between the ROC curves of HI 1 and HI 2 ( $P=0.038)$, between the ROC curves of HI 2 and HI $4(P=0.048)$, and HI 4 and HI $5(P=0.015)$.

The critical value that can be considered to indicate relevant emphysema heterogeneity with regard to ELVR for the

Table 4 ROC curve analysis to determine the predictive accuracy of the different HIs with respect to FEV, improvement after ELVR

\begin{tabular}{lllll}
\hline $\begin{array}{l}\text { Heterogeneity } \\
\text { index }\end{array}$ & $\begin{array}{l}\text { Area under } \\
\text { the ROC curve }\end{array}$ & P-value & Two-sided 95\% CI \\
\hline HI I & 0.67 & 0.050 & 0.5 I & 0.83 \\
HI 2 & 0.65 & 0.074 & 0.49 & 0.82 \\
HI 3 & 0.69 & $0.030^{*}$ & 0.53 & 0.85 \\
HI 4 & 0.73 & $0.008^{*}$ & 0.58 & 0.87 \\
HI 5 & 0.7 I & $0.016^{*}$ & 0.56 & 0.85 \\
HI 6 & 0.72 & $0.009^{*}$ & 0.58 & 0.87 \\
\hline
\end{tabular}

Note: *Statistically significant.

Abbreviations: $\mathrm{Cl}$, confidence interval; ELVR, endoscopic lung volume reduction; $\mathrm{FEV}_{\mathrm{I}}$, forced expiratory volume in I second; $\mathrm{HI}$, heterogeneity index; $\mathrm{ROC}$, receiveroperating characteristic. sensitivity and specificity level specified in Table 5 is $\sim 9.47 \%$ for HI 6 and $\sim 16.55 \%$ for HI 4 (Table 5 and Figure 2). The critical value of HI $6=9.47$ yielded similarly good sensitivity and specificity with a 0.66 and 0.78 , respectively. The critical value of HI $4=16.55 \%$ may be better when striving for higher specificity (specificity $=0.89$ ) at the cost of lower sensitivity (sensitivity $=0.47$ ).

Interestingly enough, in subgroup analysis of the patients with a tendency toward upper lobe predominant emphysema and upper lobe treatment $\mathrm{HI} 3$, HI 4, HI 5, and HI 6 showed a statistically significant discriminatory capacity between clinically successful and unsuccessful treatment assessed by $\mathrm{FEV}_{1}$ increase and yielded better predictive accuracies than the analysis of the entire patient population with areas under the curve ranging from 0.82 to 0.88 (Table 6 and Figure 3). On the other hand, in subgroup analysis of patients with a tendency toward lower lobe predominant emphysema and lower lobe treatment, none of the HIs showed a statistically significant discriminatory capacity between clinically successful and unsuccessful treatment assessed in $\mathrm{FEV}_{1}$ increase (Table 7 and Figure 4).

In Table S4, we also show the results of the ROC analysis of all 62 patients; these results are similar yet slightly less compelling than the above-described analysis

Table 5 Critical values of the $\mathrm{HI} 6$ and $\mathrm{HI} 4$ with their respective sensitivity and specificity that can be considered to identify relevant emphysema heterogeneity with regard to the prediction of significant improvement in FEV, after ELVR

\begin{tabular}{|c|c|c|c|c|c|}
\hline $\begin{array}{l}\text { Point on } \\
\text { the ROC } \\
\text { curve }\end{array}$ & $\begin{array}{l}\text { Distance to } \\
\text { left upper } \\
\text { corner }\end{array}$ & Sensitivity & Specificity & $\begin{array}{l}\text { Critical } \\
\text { value } \\
\text { of } \mathrm{HI}\end{array}$ & HI \\
\hline I & $0.4 I$ & 0.66 & 0.78 & 9.47 & 6 \\
\hline 2 & 0.54 & 0.47 & 0.89 & 16.55 & 4 \\
\hline
\end{tabular}

Notes: The critical value is the value for which the point on the ROC curve has the smallest distance to the upper left corner (see Figures I and 2). This distance (D) was calculated using the following formula: $D=\sqrt{ }\left([I-\text { sensitivity }]^{2}+[I-\text { specificity }]^{2}\right)$.

Abbreviations: ELVR, endoscopic lung volume reduction; $\mathrm{FEV}_{1}$, forced expiratory volume in I second; $\mathrm{HI}$, heterogeneity index; ROC, receiver-operating characteristic. 


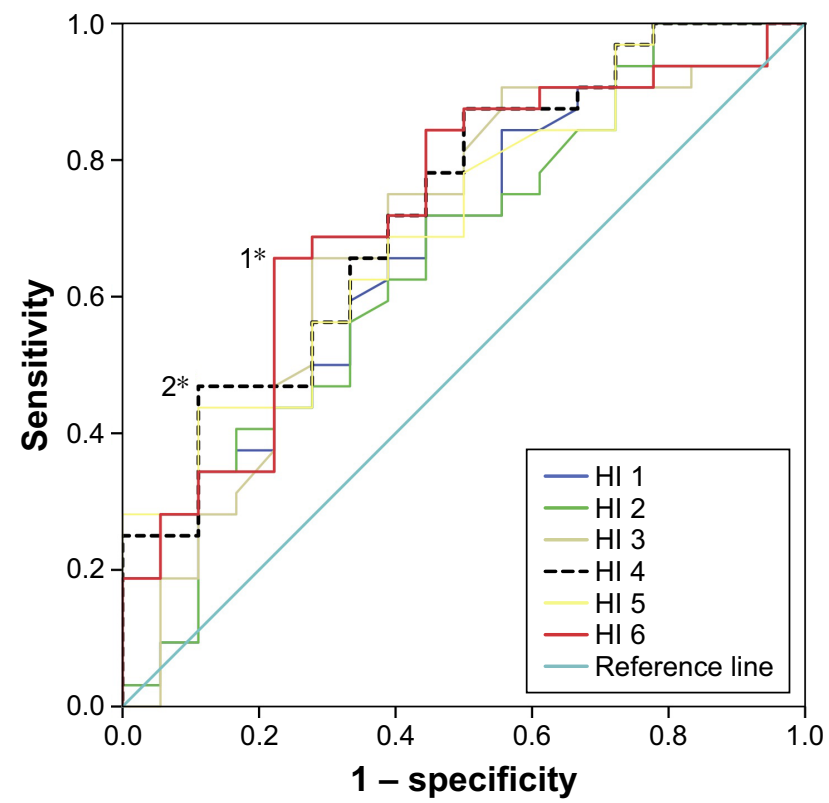

Figure 2 ROC of all Hls.

Note: *I-2 flag the values closest to the upper left corner.

Abbreviations: $\mathrm{HI}$, heterogeneity index; ROC, receiver-operating characteristic.

of the 50 patients, with a TL reduction of more than $350 \mathrm{~mL}$.

None of the HIs showed a statistically significant discriminatory capacity between clinically successful and unsuccessful treatment assessed with other output parameters like RV, SGRQ, or 6MWT. Detailed results of the analyses with these output parameters are given in Tables S5-S7.

\section{Discussion}

This study indicates that when determining an interlobar $\mathrm{HI}$, generally speaking, subtracting the percentages of emphysematous lung volume of the lobes in question yields

Table 6 ROC curve analysis of all patients with a tendency toward upper lobe predominant emphysema and upper lobe treatment $(n=24)$ to determine the predictive accuracy of the different Hls with respect to FEV, improvement after ELVR, assuming an increase in $\mathrm{FEV}$, of $100 \mathrm{~mL}$ to indicate MCID

\begin{tabular}{lllll}
\hline $\begin{array}{l}\text { Heterogeneity } \\
\text { index }\end{array}$ & $\begin{array}{l}\text { Area under } \\
\text { the ROC curve }\end{array}$ & P-value & Two-sided 95\% Cl \\
\hline $\mathrm{HI} \mathrm{I}$ & 0.77 & 0.053 & 0.49 & 1.00 \\
$\mathrm{HI} 2$ & 0.76 & 0.067 & 0.48 & 1.00 \\
$\mathrm{HI} 3$ & 0.88 & $0.007^{*}$ & 0.73 & 1.00 \\
$\mathrm{HI} 4$ & 0.84 & $0.014^{*}$ & 0.66 & 1.00 \\
$\mathrm{HI} 5$ & 0.82 & $0.023^{*}$ & 0.62 & 1.00 \\
$\mathrm{HI} 6$ & 0.87 & $0.008^{*}$ & 0.72 & 1.00 \\
\hline
\end{tabular}

Note: MCID as per Jones et al. ${ }^{29} *$ Statistically significant.

Abbreviations: $\mathrm{Cl}$, confidence interval; ELVR, endoscopic lung volume reduction; $F E V_{1}$, forced expiratory volume in one second; $\mathrm{HI}$, heterogeneity index; MCID, minimal clinically important difference; ROC, receiver-operating characteristic.

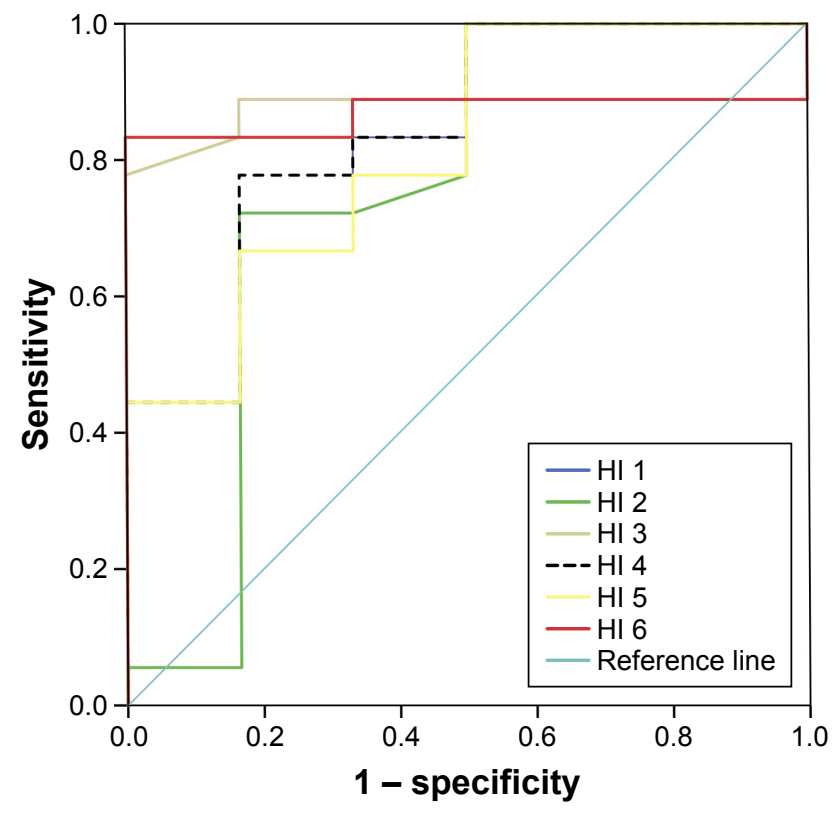

Figure 3 Receiver-operating characteristic of all patients with a tendency toward upper lobe predominant emphysema and upper lobe treatment $(n=24)$. Abbreviation: $\mathrm{HI}$, heterogeneity index.

better predictive accuracy in ROC analysis than dividing them. Furthermore, the results suggest that disregarding the right middle lobe, as done in the VENT study by Sciurba et al, is reasonable. ${ }^{1}$ Defining the $\mathrm{HI}$ as the emphysema score of the TL minus emphysema score of the lung without the TL, that is, HI 6, seems to be the most intuitive approach with regard to ELVR from our point of view, as the percentage of emphysematous lung tissue of the remaining lung is compared with that of the lung lobe about to be removed by means of atelectasis induction. Indeed, our results confirm that this definition yields good predictive accuracy in the $\mathrm{ROC}$ analysis $(\mathrm{AUC}=0.72, P=0.009)$. Interestingly enough,

Table 7 ROC curve analysis of all patients with a tendency toward lower lobe predominant emphysema and lower lobe treatment $(n=38)$ to determine the predictive accuracy of the different Hls with respect to FEV, improvement after ELVR, assuming an increase in FEV, of $100 \mathrm{~mL}$ to indicate MCID

\begin{tabular}{lllll}
\hline $\begin{array}{l}\text { Heterogeneity } \\
\text { index }\end{array}$ & $\begin{array}{l}\text { Area under } \\
\text { the ROC curve }\end{array}$ & P-value & Two sided 95\% Cl \\
\hline HI I & 0.62 & 0.198 & 0.44 & 0.80 \\
HI 2 & 0.62 & 0.225 & 0.43 & 0.80 \\
HI 3 & 0.62 & 0.219 & 0.44 & 0.80 \\
HI 4 & 0.63 & 0.161 & 0.45 & 0.81 \\
HI 5 & 0.64 & 0.148 & 0.46 & 0.82 \\
HI 6 & 0.65 & 0.121 & 0.47 & 0.82 \\
\hline
\end{tabular}

Note: $\mathrm{MCID}$ as per Jones et al. ${ }^{29}$

Abbreviations: $\mathrm{Cl}$, confidence interval; ELVR, endoscopic lung volume reduction; $\mathrm{FEV}_{1}$, forced expiratory volume in one second; $\mathrm{HI}$, heterogeneity index; MCID, minimal clinically important difference; ROC, receiver-operating characteristic. 


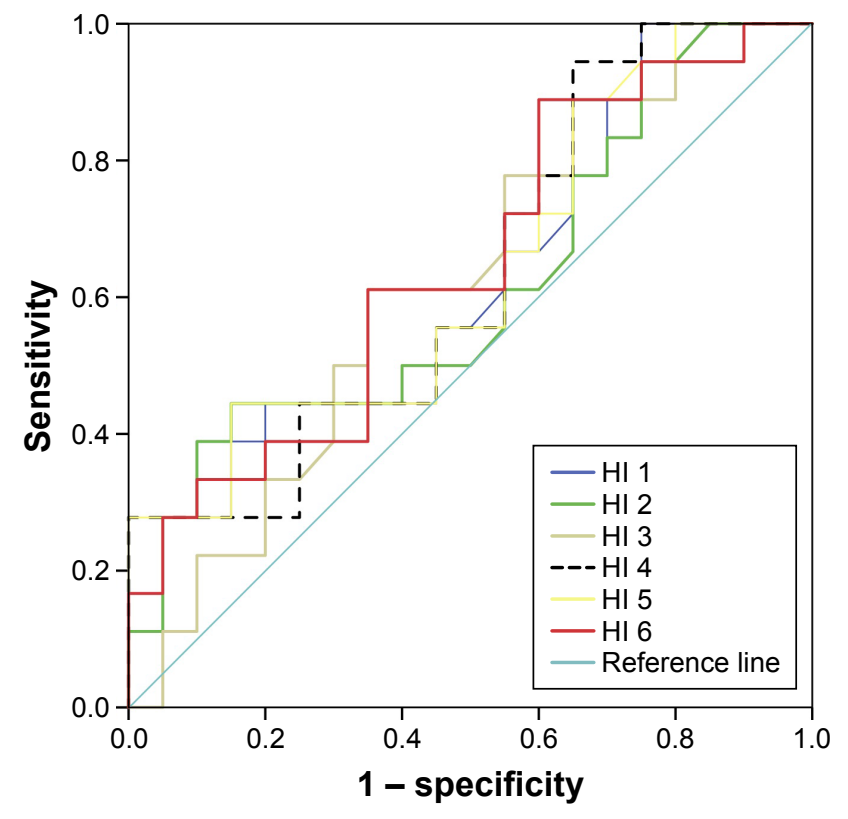

Figure 4 Receiver-operating characteristic of all patients with a tendency toward lower lobe predominant emphysema and lower lobe treatment $(n=38)$. Abbreviation: $\mathrm{HI}$, heterogeneity index.

however, this is not the definition that was used in most of the major trials published in the literature. ${ }^{1,13,32}$ Instead, in these studies, interlobar emphysema heterogeneity was defined as the emphysema score of the TL minus the emphysema score of the INTL, disregarding the middle lobe, that is, HI 4 in our analysis, which surprisingly enough also yielded the best predicative accuracy (AUC $=0.73, P=0.008$ ). However, when tested with DeLong's test for two correlated ROC curves, H4 was only significantly different from HI 2 and HI 5, while HI 6 was not significantly different from any of the other HIs. The elucidated best definitions of HI should therefore be considered as a recommendation only and further studies are needed to validate the results.

When clinicians and investigators claim that interlobar emphysema heterogeneity has a relevant impact on the outcome of lung volume reduction and therefore should be taken into consideration when evaluating candidates for this treatment, it is only fair to ask what a relevant interlobar emphysema heterogeneity is. This study may give an answer to that question. When striving for equally good sensitivity and specificity, HI 6 performed the best with a threshold for identifying relevant emphysema heterogeneity in terms of ELVR treatment of $\sim 9.47 \%$. This is a notable result as there seems to be a need for such a cutoff value given that even very recent studies are still referring to the somewhat arbitrary definition of heterogeneous emphysema based on visual analysis as known from the National Emphysema Treatment Trial published in $2001 .^{11,33,34}$ It needs to be emphasized, though, that while these cutoff values give a good first orientation, further studies are needed to validate and adjust the exact cutoff value as a patient population of 50 is still too small for generalization.

Although in accordance with the recently published paper from Thomsen et al, ${ }^{12}$ the fact that none of the HIs showed a statistically significant discriminatory capacity between clinically successful and unsuccessful treatment assessed with the 6MWT, the SGRQ or the RV reduction might also be due to the small population size. A bigger study is needed to validate this result.

Subgroup analysis of the patient population revealed that in patients with predominantly lower lobe emphysema and lower lobe treatment, none of the HIs had a statistically significant discriminatory capacity between clinically successful and unsuccessful treatment assessed by $\mathrm{FEV}_{1}$ improvement, whereas in patients with predominantly upper lobe emphysema and upper lobe treatment, HI 3, HI 4, HI 5, and HI 6 showed a statistically significant and rather good discriminatory capacity. This suggests that emphysema heterogeneity might indeed only be of importance when dealing with upper lobe predominant emphysema and upper lobe treatment.

\section{Limitations of the study}

Our study has several limitations, notably its retrospective design and the aforementioned patient population size of only 50, which constitutes a major limitation. For this reason, this study can only serve as a preliminary study and further studies are needed to validate the results.

Furthermore, there are factors other than the emphysema heterogeneity that affect the outcome of ELVR such as collateral ventilation, lobar perfusion, and air trapping. However, since these other factors affect all differently defined HIs in the ROC analysis equally, we are convinced that our results remain valid. The fact that there are other factors that affect $\mathrm{FEV}_{1}$ improvement after ELVR might, in turn, explain the overall only fair discriminatory capacity of the HIs. It must be emphasized, though, that these other factors mentioned previously must also be considered when evaluating a patient for lobar lung volume reduction therapy.

Another limitation of the study is the fact that the results and conclusion are based on the analysis using $\mathrm{FEV}_{1}$ as the outcome parameter and somewhat neglected the other important output parameters such as change in 6MWT test or quality of life. ${ }^{35}$ Having said that, though, FEV 1 has been recognized as an objective index of airflow obstruction by the COPD research community and regulatory agencies. ${ }^{36}$ 


\section{Conclusion}

Based on the ROC analysis of this study, we recommend determining the HI of the lobe in question for ELVR by subtracting the emphysema score of the lung without the TL from the emphysema score of the TL, or alternatively, by subtracting the emphysema score of the INTL from the emphysema score of the TL, disregarding the middle lobe. The impact of interlobar emphysema heterogeneity seems to be of greater importance in patients with upper lobe predominant emphysema and upper lobe treatment than in patients with lower lobe predominant emphysema and lower lobe treatment.

\section{Acknowledgments}

D Theilig is a participant in the Charité Junior Clinical Scientist Program and V Schreiter is a participant in the Charité Clinical Scientist Program funded by Charité - Universitätsmedizin Berlin and the Berlin Institute of Health. The authors thank Dominik Herzog and Christian Thomsen for data collection and Bettina Herwig for language editing.

\section{Disclosure}

Dr Ralf-Harto Hubner has received lecture fees and devices from Pulmonx, the company producing the one-way valves. The authors report no other conflicts of interest in this work.

\section{References}

1. Sciurba FC, Ernst A, Herth FJ, et al. A randomized study of endobronchial valves for advanced emphysema. $N$ Engl J Med. 2010;363(13): 1233-1244.

2. Davey C, Zoumot Z, Jordan S, et al. Bronchoscopic lung volume reduction with endobronchial valves for patients with heterogeneous emphysema and intact interlobar fissures (the BeLieVeR-HIFi study): a randomised controlled trial. Lancet. 2015;386(9998):1066-1073.

3. Shah PL, Herth FJ. Current status of bronchoscopic lung volume reduction with endobronchial valves. Thorax. 2014;69(3):280-286.

4. Park TS, Hong Y, Lee JS, et al. Efficacy of bronchoscopic lung volume reduction by endobronchial valves in patients with heterogeneous emphysema: report on the first Asian cases. J Korean Med Sci. 2014;29(10):1404-1410.

5. Park TS, Hong Y, Lee JS, et al. Bronchoscopic lung volume reduction by endobronchial valve in advanced emphysema: the first Asian report. Int J Chron Obstruct Pulmon Dis. 2015;10:1501-1511.

6. Koegelenberg CF, Theron J, Bruwer JW, et al. Endoscopic lung volume reduction in severe emphysema. S Afr Med J. 2015;105(9):721-723.

7. Valipour A, Burghuber OC. An update on the efficacy of endobronchial valve therapy in the management of hyperinflation in patients with chronic obstructive pulmonary disease. Ther Adv Respir Dis. 2015;9(6):294-301.

8. Klooster K, ten Hacken NH, Hartman JE, Kerstjens HA, van Rikxoort EM, Slebos DJ. Endobronchial valves for emphysema without interlobar collateral ventilation. $N$ Engl J Med. 2015;373(24): 2325-2335.

9. Gompelmann D, Eberhardt R, Herth FJ. Interventional pulmonology procedures: an update. Panminerva Med. 2013;55(2):121-129.

10. Gompelmann D, Sarmand N, Herth FJ. Interventional pulmonology in chronic obstructive pulmonary disease. Curr Opin Pulm Med. 2017; 23(3):261-268.
11. Davey C, Zoumot Z, Jordan S, et al. Bronchoscopic lung volume reduction with endobronchial valves for patients with heterogeneous emphysema and intact interlobar fissures (the BeLieVeR-HIFi trial): study design and rationale. Thorax. 2015;70(3):288-290.

12. Thomsen C, Theilig D, Herzog D, et al. Lung perfusion and emphysema distribution affect the outcome of endobronchial valve therapy. Int J Chron Obstruct Pulmon Dis. 2016;11:1245-1259.

13. Herth FJ, Noppen M, Valipour A, et al. Efficacy predictors of lung volume reduction with Zephyr valves in a European cohort. Eur Respir J. 2012;39(6):1334-1342.

14. Valipour A, Shah PL, Gesierich W, et al. Patterns of emphysema heterogeneity. Respiration. 2015;90(5):402-411.

15. Schuhmann M, Raffy P, Yin Y, et al. Computed tomography predictors of response to endobronchial valve lung reduction treatment. Comparison with Chartis. Am J Respir Crit Care Med. 2015;191(7): 767-774.

16. Gompelmann D, Eberhardt R, Slebos DJ, et al. Diagnostic performance comparison of the Chartis System and high-resolution computerized tomography fissure analysis for planning endoscopic lung volume reduction. Respirology. 2014;19(4):524-530.

17. Wan IY, Toma TP, Geddes DM, et al. Bronchoscopic lung volume reduction for end-stage emphysema: report on the first 98 patients. Chest. 2006;129(3):518-526.

18. Herth FJ, Eberhardt R, Gompelmann D, et al. Radiological and clinical outcomes of using Chartis to plan endobronchial valve treatment. Eur Respir J. 2013;41(2):302-308.

19. Kuhnigk JM, Dicken V, Zidowitz S, et al. Informatics in radiology (infoRAD): new tools for computer assistance in thoracic CT. Part 1. Functional analysis of lungs, lung lobes, and bronchopulmonary segments. Radiographics. 2005;25(2):525-536.

20. Gevenois PA, De Vuyst P, de Maertelaer V, et al. Comparison of computed density and microscopic morphometry in pulmonary emphysema. Am J Respir Crit Care Med. 1996;154(1):187-192.

21. Wang Z, Gu S, Leader JK, et al. Optimal threshold in CT quantification of emphysema. Eur Radiol. 2013;23(4):975-984.

22. Lynch DA, Al-Qaisi MA. Quantitative computed tomography in chronic obstructive pulmonary disease. J Thorac Imaging. 2013;28(5): 284-290.

23. Matsuo K, Iwano S, Okada T, Koike W, Naganawa S. 3D-CT lung volumetry using multidetector row computed tomography: pulmonary function of each anatomic lobe. J Thorac Imaging. 2012;27(3): 164-170.

24. Valipour A, Herth FJ, Eberhardt R, et al. Design of the randomized, controlled sequential staged treatment of emphysema with upper lobe predominance (STEP-UP) study. BMC Pulm Med. 2014; 14:190.

25. Bandyopadhyay S, Henne E, Gupta A, et al. Segmental approach to lung volume reduction therapy for emphysema patients. Respiration. 2015;89(1):76-81

26. Herth FJ, Valipour A, Shah PL, et al. Segmental volume reduction using thermal vapour ablation in patients with severe emphysema: 6-month results of the multicentre, parallel-group, open-label, randomised controlled STEP-UP trial. Lancet Respir Med. 2016;4(3):185-193.

27. Park SH, Goo JM, Jo CH. Receiver operating characteristic (ROC) curve: practical review for radiologists. Korean J Radiol. 2004;5(1): $11-18$.

28. Donohue JF. Minimal clinically important differences in COPD lung function. COPD. 2005;2(1):111-124.

29. Jones PW, Beeh KM, Chapman KR, Decramer M, Mahler DA, Wedzicha JA. Minimal clinically important differences in pharmacological trials. Am J Respir Crit Care Med. 2014;189(3):250-255.

30. Cazzola M, MacNee W, Martinez FJ, Rabe KF. Outcomes for COPD pharmacological trials: from lung function to biomarkers. Rev Port Pneumol. 2008;14(4):579-583.

31. Hajian-Tilaki K. Receiver Operating Characteristic (ROC) curve analysis for medical diagnostic test evaluation. Caspian J Intern Med. 2013;4(2):627-635. 
32. Fiorelli A, Petrillo M, Vicidomini G, et al. Quantitative assessment of emphysematous parenchyma using multidetector-row computed tomography in patients scheduled for endobronchial treatment with one-way valvesdagger. Interact Cardiovasc Thorac Surg. 2014;19(2): 246-255.

33. Boutou AK, Zoumot Z, Nair A, et al. The impact of homogeneous versus heterogeneous emphysema on dynamic hyperinflation in patients with severe COPD assessed for lung volume reduction. COPD. 2015;12(6):598-605.

34. National Emphysema Treatment Trial Research Group, Fishman A, Fessler H, Martinez F, et al. Patients at high risk of death after lungvolume-reduction surgery. $N$ Engl J Med. 2001;345(15):1075-1083.
35. Vestbo J, Hurd SS, Agusti AG, et al. Global strategy for the diagnosis, management, and prevention of chronic obstructive pulmonary disease: GOLD executive summary. Am J Respir Crit Care Med. 2013;187(4): 347-365.

36. CPMP. Points to consider on clinical investigation od medicinal products in the chronic treatment of patients with chronic obstructive pulmonary disease (COPD). European Agency for the Evaluation of Medical Products. 1999:London, CPMP/EWP/562/598. 


\section{Supplementary materials}

Table SI ROC curve analysis of all patients $(n=62)$ to determine the predictive accuracy of the different volume-weighted $\mathrm{Hls}(\mathrm{HI}$ * targeted lobe volume) with respect to $\mathrm{FEV}_{\text {, increased after }}$ ELVR assuming an increase in $\mathrm{FEV}$, of $100 \mathrm{~mL}$ to indicate MCID

\begin{tabular}{lllll}
\hline $\begin{array}{l}\text { Volume- } \\
\text { weighted HIs }\end{array}$ & $\begin{array}{l}\text { Area under } \\
\text { the ROC curve }\end{array}$ & P-value & \multicolumn{2}{c}{ Two-sided 95\% Cl } \\
\hline $\mathrm{HI} \mathrm{I'}$ & 0.64 & 0.066 & 0.50 & 0.78 \\
$\mathrm{HI} 2^{\prime}$ & 0.64 & 0.056 & 0.50 & 0.78 \\
$\mathrm{HI} 3^{\prime}$ & $0.6 \mathrm{I}$ & 0.127 & 0.47 & 0.76 \\
$\mathrm{HI} 4^{\prime}$ & 0.66 & $0.030^{*}$ & 0.52 & 0.80 \\
$\mathrm{HI} \mathrm{5'}$ & 0.66 & $0.034^{\prime}$ & 0.52 & 0.80 \\
$\mathrm{HI} \mathrm{6}$ & 0.66 & $0.039^{\prime}$ & $0.5 \mathrm{I}$ & 0.80
\end{tabular}

Note: MCID as per Jones et al.'

Abbreviations: $\mathrm{Cl}$, confidence interval; ELVR, endoscopic lung volume reduction FEV , forced expiratory volume in I second; $\mathrm{HI}$, heterogeneity index; MCID, minimal clinically important difference; ROC, receiver-operating characteristic.

Table S2 Definitions of the additional Hls calculated from the TAR

\begin{tabular}{ll}
$\begin{array}{l}\text { Heterogeneity } \\
\text { index }\end{array}$ & Definition \\
\hline HI 7 & TAR of TL/TAR of the INTL excluding middle lobe \\
HI 8 & TAR of TL/TAR of the INTL including middle lobe \\
HI 9 & TAR of TL/TAR of the whole lung without TL \\
\hline
\end{tabular}

Abbreviations: $\mathrm{HI}$, heterogeneity index; INTL, ipsilateral nontargeted lobe; TAR, tissue to air ratio; TL, targeted lobe.

Table S3 ROC curve analysis of all patients $(n=62)$ to determine the predictive accuracy of Hls calculated from the TAR with respect to $F E V$, change after ELVR assuming an increase of FEV , of $100 \mathrm{~mL}$ to indicate MCID

\begin{tabular}{lllll}
\hline $\begin{array}{l}\text { Heterogeneity } \\
\text { index }\end{array}$ & $\begin{array}{l}\text { Area under } \\
\text { the ROC curve }\end{array}$ & P-value & Two-sided 95\% Cl \\
\hline $\mathrm{HI} 7$ & 0.62 & 0.104 & 0.48 & 0.77 \\
$\mathrm{HI} 8$ & 0.65 & $0.04 I^{*}$ & 0.52 & 0.79 \\
$\mathrm{HI} 9$ & 0.67 & $0.025^{*}$ & 0.53 & $0.8 \mathrm{I}$ \\
\hline
\end{tabular}

Notes: In this ROC analysis, negative outcome is predicted, as the lower the TAR the higher the severity of the disease and vice versa (Bandyopadhyay et $\mathrm{al}^{2}$ ). *Statistically significant. MCID as per Jones et al.'

Abbreviations: $\mathrm{Cl}$, confidence interval; ELVR, endoscopic lung volume reduction; $\mathrm{FEV}_{\text {, }}$, forced expiratory volume in I second; HI, heterogeneity index; ROC, receiveroperating characteristic; TAR, tissue to air ratio.

Table S4 ROC curve analysis of all patients $(n=62)$ to determine the predictive accuracy of the different Hls with respect to FEV, improvement after ELVR assuming an increase in FEV, of $100 \mathrm{~mL}$ to indicate MCID

\begin{tabular}{lllll}
\hline $\begin{array}{l}\text { Heterogeneity } \\
\text { index }\end{array}$ & $\begin{array}{l}\text { Area under } \\
\text { the ROC curve }\end{array}$ & P-value & Two-sided 95\% Cl \\
\hline HI I & 0.64 & 0.07 I & 0.49 & 0.78 \\
HI 2 & 0.64 & 0.065 & 0.50 & 0.78 \\
HI 3 & 0.66 & $0.039 *$ & 0.5 I & 0.80 \\
HI 4 & 0.66 & $0.03 I^{*}$ & 0.52 & 0.80 \\
HI 5 & 0.66 & $0.035^{*}$ & 0.52 & 0.80 \\
HI 6 & 0.68 & $0.019 *$ & 0.54 & 0.8 I \\
\hline
\end{tabular}

Notes: MCID as per Jones et al.' *Statistically significant.

Abbreviations: $\mathrm{Cl}$, confidence interval; ELVR, endoscopic lung volume reduction; $\mathrm{FEV}_{1}$, forced expiratory volume in I second; $\mathrm{HI}$, heterogeneity index; MCID, minimal clinically important difference; ROC, receiver-operating characteristic.
Table S5 ROC curve analysis of all patients with available 6MWT results $(n=44)$ to determine the predictive accuracy of the different Hls with respect to 6MWT improvement after ELVR, assuming an increase in 6MWT of 26 minutes to indicate MCID

\begin{tabular}{lllll}
\hline $\begin{array}{l}\text { Heterogeneity } \\
\text { index }\end{array}$ & $\begin{array}{l}\text { Area under } \\
\text { the ROC curve }\end{array}$ & P-value & Two-sided 95\% Cl \\
\hline HI I & 0.53 & 0.750 & 0.35 & 0.70 \\
HI 2 & 0.53 & 0.697 & 0.36 & 0.70 \\
HI 3 & 0.52 & 0.850 & 0.34 & 0.69 \\
HI 4 & 0.53 & 0.768 & 0.35 & 0.70 \\
HI 5 & 0.53 & 0.777 & 0.35 & 0.70 \\
HI 6 & 0.52 & 0.832 & 0.34 & 0.69 \\
\hline
\end{tabular}

Note: MCID as per Jones et al.'

Abbreviations: $\mathrm{Cl}$, confidence interval; ELVR, endoscopic lung volume reduction; $\mathrm{HI}$, heterogeneity index; MCID, minimal clinically important difference; ROC, receiver-operating characteristic; 6MWT, 6-minute walk test.

Table S6 ROC curve analysis of all patients with available SGRQ test results $(n=47)$ to determine the predictive accuracy of the different Hls with respect to SGRQ improvement after ELVR, assuming an increase in SGRQ of 4 units to indicate MCID

\begin{tabular}{lllll}
\hline $\begin{array}{l}\text { Heterogeneity } \\
\text { index }\end{array}$ & $\begin{array}{l}\text { Area under } \\
\text { the ROC curve }\end{array}$ & P-value & Two-sided 95\% Cl \\
\hline HI I & 0.59 & 0.346 & 0.4 I & 0.76 \\
HI 2 & 0.58 & 0.375 & 0.40 & 0.76 \\
HI 3 & 0.50 & 0.991 & 0.32 & 0.68 \\
HI 4 & 0.55 & 0.567 & 0.37 & 0.73 \\
HI 5 & 0.55 & 0.613 & 0.37 & 0.73 \\
HI 6 & 0.48 & 0.840 & 0.30 & 0.67 \\
\hline
\end{tabular}

Note: MCID as per Jones et al.'

Abbreviations: $\mathrm{Cl}$, confidence interval; ELVR, endoscopic lung volume reduction; $\mathrm{HI}$, heterogeneity index; MCID, minimal clinically important difference; ROC, receiver-operating characteristic; SGRQ, St George's Respiratory Questionnaire.

Table S7 ROC curve analysis of all patients $(n=62)$ to determine the predictive accuracy of the different Hls with respect to RV reduction after ELVR, assuming a decrease in $R V$ of $0.3 \mathrm{I} L$ to indicate MCID

\begin{tabular}{lllll}
\hline $\begin{array}{l}\text { Heterogeneity } \\
\text { index }\end{array}$ & $\begin{array}{l}\text { Area under } \\
\text { the ROC curve }\end{array}$ & P-value & Two-sided 95\% Cl \\
\hline $\mathrm{HI} \mathrm{I}$ & 0.57 & $0.34 \mathrm{I}$ & 0.43 & $0.7 \mathrm{I}$ \\
$\mathrm{HI} 2$ & 0.57 & 0.317 & 0.43 & 0.72 \\
$\mathrm{HI} 3$ & 0.58 & 0.259 & 0.44 & 0.73 \\
$\mathrm{HI} 4$ & 0.56 & 0.393 & 0.42 & $0.7 \mathrm{I}$ \\
$\mathrm{HI} 5$ & 0.56 & 0.413 & 0.42 & $0.7 \mathrm{I}$ \\
$\mathrm{HI} 6$ & 0.57 & 0.355 & 0.42 & $0.7 \mathrm{I}$ \\
\hline
\end{tabular}

Note: MCID as per Jones et al.

Abbreviations: $\mathrm{Cl}$, confidence interval; ELVR, endoscopic lung volume reduction; $\mathrm{HI}$, heterogeneity index; MCID, minimal clinically important difference; ROC, receiver-operating characteristic; $\mathrm{RV}$, residual volume.

\section{References}

1. Jones PW, Beeh KM, Chapman KR, Decramer M, Mahler DA, Wedzicha JA. Minimal clinically important differences in pharmacological trials. Am J Respir Crit Care Med. 2014;189(3):250-255.

2. Bandyopadhyay S, Henne E, Gupta A, et al. Segmental approach to lung volume reduction therapy for emphysema patients. Respiration. 2015; 89(1):76-81. 


\section{Publish your work in this journal}

The International Journal of COPD is an international, peer-reviewed journal of therapeutics and pharmacology focusing on concise rapid reporting of clinical studies and reviews in COPD. Special focus is given to the pathophysiological processes underlying the disease, intervention programs, patient focused education, and self management protocols.

This journal is indexed on PubMed Central, MedLine and CAS. The manuscript management system is completely online and includes a very quick and fair peer-review system, which is all easy to use. Visit http://www.dovepress.com/testimonials.php to read real quotes from published authors. 